- Defects in nitrile gloves prior to use may not be significantly different in number from natural latex gloves.

- Nitrile gloves may provide satisfactory barrier protection and could be of value to dental healthcare workers (DHCWs) who have allergies to natural rubber latex.

\title{
A preliminary report on the incidence of pre-existing pinhole defects in nitrile dental gloves
}

\author{
H. B. Patel, ${ }^{1}$ G. J. P. Fleming ${ }^{2}$ and F. J. Trevor Burke ${ }^{3}$
}

Introduction Examination gloves manufactured from natural latex have been the predominant glove choice to date in dental practice. However, concerns over hypersensitivity have resulted in the use of alternatives such as nitrile gloves. The aim of the current study was to assess the incidence of pre-existing pinhole defects in nitrile examination gloves.

Methods Air inflation, followed by water submersion, was used to assess the incidence of pre-existing pinhole defects in five nitrile and two latex glove types. The gloves were filled with a constant volume of air and submerged in 3 litres of water for 10 seconds while being observed for air bubbles which would indicate pinhole defects. The position and number of pinholes were noted for 100 gloves of each type investigated.

Results The incidence of pre-existing pinholes for latex gloves was $0 \%$ for the non-sterile surgical latex glove type and 3\% for the powdered latex examination glove type, with pinholes located on the thumb, middle finger and ring finger. Of the nitrile gloves evaluated, three types were assessed to have no pre-existing pinhole defects. One type had a $2 \%$ incidence of pre-existing pinhole defects - one pinhole located on the thumb region of the glove and one on the ring finger portion of the glove. The fifth nitrile glove type had one pre-existing pinhole defect located on the middle finger.

Significance All glove types examined met the European Standard (EN 455-1) and there was no statistically significant difference between glove types. However, the nitrile gloves generally exhibited less pre-existing pinhole defects than the latex examination gloves.

Gloves provide barrier protection for the dental healthcare professional against microorganisms and, in particular, blood borne

${ }^{1}$ Research Assistant, ${ }^{2}$ Lecturer, Biomaterials Unit, ${ }^{3}$ Professor of Primary Dental Care, Primary Dental Care Research Group, School of Dentistry, University of Birmingham, St. Chad's Queensway, Birmingham B4 6NN, United Kingdom.

Correspondence to: Garry J.P. Fleming, Lecturer in Dental Biomaterials, Biomaterials Unit, School of Dentistry, The University of Birmingham, St. Chad's Queensway, Birmingham B4 6NN

E-Mail:G.J.Fleming@bham.ac.uk

\section{Refereed paper}

Received 25.06.02; Accepted 17.01.03

doi:10.1038/sj.bdj.4810667

$\odot$ British Dental Journal 2003; 195: 509-512 viruses such as hepatitis B. They also provide barrier protection against chemicals that are routinely used in dental procedures. As a consequence, the routine wearing of gloves is an essential requirement for operator and patient safety. ${ }^{1-7}$ Ramos-Gomez et al. ${ }^{8}$ highlighted that dental operators had the highest risk of accidental exposure to blood and body fluids when compared with all healthcare service providers. Exposures were categorised as skin punctures or cuts, needlestick injuries, splashes into the face or eyes and bites from patients. ${ }^{8}$

Routine dental procedures prior to 1970 could be divided into surgical and non-surgical categories. ${ }^{9}$ Surgical procedures followed aseptic techniques, however, the operators did not always wear gloves. In the early 1980s the increasing prevalence of HIVinfection changed the perception of infection control for both dentists and dental regulatory bodies. ${ }^{1-2,6}$ As a result, the concept of 'universal precautions', whereby operators treated body fluids from patients as though they were infected, was developed. ${ }^{10-11}$

Hepatitis B has been recognised as the most pervasive occupational communicable disease among dentists and transmission may occur through microscopic skin lesions or more frequently through percutaneous injuries from sharp instruments contaminated by body fluid. ${ }^{13}$ Kearns et al. ${ }^{14}$ highlighted that minute breaks can occur in the epidermis adjacent to the fingernail therefore offering a potential site for microorganisms to invade. Blood containing associated pathogens may also become entrapped in the fingernail and may be passed on to the next patient. The European Panel for Infection Control in Dentistry (EPICD) recommended the wearing of gloves to reduce the risk of contamination for all persons directly and indirectly involved in dental treatment. ${ }^{15}$ As a result, the use of protective gloves by dental health care workers (DHCWs) has increased ${ }^{15,16}$ due to safety and possible concerns regarding litigation.

The majority of gloves used in dentistry and medicine are manufactured from latex, which consists of an emulsion of polymer in water. ${ }^{17}$ Latex gloves may contain over 15 natural polypeptides and additives to the polymer solution that have the potential to cause hypersensitivity. It has been considered that $7 \%-10 \%$ of healthcare workers suffer from some type of allergic response. ${ }^{18}$ Both natural latex and synthetic latex gloves may be implicated in hypersensitivity. 
Clinical latex allergy is manifested in several forms, the most common being contact dermatitis, which is a non-allergenic cutaneous response to prolonged glove exposure combined with sweating and abrasion. ${ }^{18-19}$ Contact dermatitis may occur as an occupational hazard to dentists in particular, as they tend to routinely wear gloves for long periods of time. Type I (immediate) hypersensitive reactions to latex may cause contact urticaria or even anaphylaxis. ${ }^{18,19}$ Field et al. $^{20}$ considered that the occurrence of type I hypersensitivity to natural rubber latex had increased over the past 20 years with both patients and dentists being affected. In this respect, Amin et al. ${ }^{18}$ reported that $18.5 \%$ (22 of 119) of dental students and 22.8\% (39 of 171) of qualified dentists in a dental school in Indiana, had developed adverse skin reactions to latex dental gloves.

As a result of the associated adverse skin reactions to latex, dental glove manufacturers have attempted to produce gloves from synthetic latex. The move away from natural rubber latex (NRL) towards synthetic latex in dentistry was led by the introduction of polyvinyl chloride (PVC) and, more recently, nitrile gloves. Unfortunately, PVC gloves are prone to pre-existing pinhole defects, ${ }^{21}$ exhibit a low puncture resistance ${ }^{22}$ and are reported to significantly decrease in integrity under the stresses of clinical use, compared with latex gloves. ${ }^{23}$ As a result, attention has recently been focused on nitrile gloves as a possible alternative to dental gloves manufactured from natural latex. Nitrile gloves are made of a synthetic co-polymer of acrylonitrile and butadiene, ${ }^{24}$ which forms an emulsion in water often referred to as synthetic latex. To date, inadequate information exists in the scientific literature regarding the properties of nitrile gloves and their performance in clinical practice.

Glove manufacturers assess gloves for pre-existing pinhole defects using the European Standard EN 455-125. The document states that the water tightness test, in which the glove is filled with one litre of water and assessed for leaks, may be replaced by any test that is validated against it. The detection of pre-existing pinhole defects has previously been assessed using either a water inflation technique, ${ }^{25-29}$ an air inflation/water submersion technique $^{21,26}$ or both methods. ${ }^{26}$

The aim of the current study was to assess the incidence of preexisting pinhole defects in five types of nitrile gloves compared with two latex glove types. The air inflation/water submersion technique is more sensitive than water inflation, ${ }^{21,26}$ and therefore an adapted version of the air inflation/water submersion technique was considered to be the most appropriate method of assessing pre-existing pinhole defects in the current study.

\section{MATERIALS AND METHODS}

Seven different brands of medium non-sterile medical gloves were obtained, 100 for each glove type investigated, from five different manufacturers (Table 1). Each glove type under examination was filled with $700 \mathrm{~cm}^{3}$ of air from a compressed gas cylinder and sealed by twisting the glove at the wrist. The airtight glove was then submerged in a tank containing 3 litres of water. Gentle pressure was applied to the glove for $10 \mathrm{~s}$ while rotating it anticlockwise and the presence of air bubbles was indicative of a pre-existing pinhole defect. Following this initial examination, starting from the thumb, each finger was inflated individually with $200 \mathrm{~cm}^{3}$ of air and submerged into the tank (as described previously for the whole glove) such that the presence and location of any pre-existing pinhole defects could be noted.

For the five nitrile glove types under investigation in the current study each glove was filled with $500 \mathrm{~cm}^{2}$ of air, sealed and submerged for $10 \mathrm{~s}$ while applying gentle finger pressure. Inflation of each finger was not possible due to the relative inelasticity of nitrile gloves compared with latex glove types. ${ }^{26}$ As a result, gentle pressure was applied during submersion to the finger portions of each air inflated nitrile glove, starting from the thumb and any pre-existing pinhole defect detected was recorded.

\section{RESULTS}

For the two latex dental gloves under investigation the incidence of pre-existing pinholes identified by the adapted air inflation/water submersion technique were 3\% (3/100) and 0\% $(0 / 100)$. The three pre-existing pinholes on the powdered latex gloves were located on the thumb, middle finger and ring finger (Fig. 1). The non-sterile surgical latex glove was found to have no pre-existing pinhole defects.

Two of the five brands of nitrile dental examination gloves investigated were found to have pre-existing pinhole defects at an incidence level of $2 \%(2 / 100)$ and 1\% (1/100). Pre-existing pinholes on the former glove type were located on the thumb and ring finger (Fig. 1). The one pre-existing pinhole defect discovered in the second nitrile glove type was located on the middle finger (Fig. 1). The remaining three nitrile glove types were assessed to have no pre-existing pinhole defects (Table 1).

One way analysis of variance (ANOVA) was assessed at the 95\% significance level. There was no significant difference between the number of pinholes detected in the powdered latex examination gloves and the non-powdered non-sterile surgical latex gloves. There was also no significant difference between any of the nitrile gloves and between any of the latex gloves when compared with the nitrile gloves $(P>0.05)$

\section{DISCUSSION}

Ballbach et al. ${ }^{26}$ used the water inflation method to assess the incidence of pre-existing pinhole defects in sterile and non-sterile rubber and plastic gloves. These workers added a fixed volume of $300 \mathrm{ml}$ of water to each glove before suspending each by the cuff for 5 minutes while visual inspection was carried out for leaks. Skaug ${ }^{27}$ investigated the incidence of pre-existing pinhole defects in 50 sterile latex surgical gloves using the water inflation technique and $500 \mathrm{ml}$ of water. The open end of the glove was twisted closed and external pressure applied such that a thin jet of water was indicative of a pre-existing pinhole defect, however none were recorded. ${ }^{30}$ The water inflation technique was used by Otis and

Table 1 Glove specifications, manufacturers' details and the incidence of pre-existing pinhole defects of the five nitrile and two latex glove types investigated

\begin{tabular}{|c|c|c|c|}
\hline $\begin{array}{l}\text { Dental glove } \\
\text { type }\end{array}$ & $\begin{array}{l}\text { Batch } \\
\text { number }\end{array}$ & Manufacturer details & $\begin{array}{c}\text { Pre-existing } \\
\text { pinhole defect(s) }\end{array}$ \\
\hline $\begin{array}{l}\text { Biogel D } \\
\text { (Latex) } \\
\text { Powder Free }\end{array}$ & 01B1510 & $\begin{array}{l}\text { Regent Medical } \\
\text { (Malaysia) }\end{array}$ & $0(0 \%)$ \\
\hline $\begin{array}{l}\text { Microtouch } \\
\text { Latex } \\
\text { Powdered }\end{array}$ & 0105061721 & $\begin{array}{l}\text { Ansell Healthcare } \\
\text { Products (Malaysia) }\end{array}$ & $3(3 \%)$ \\
\hline $\begin{array}{l}\text { Microtouch } \\
\text { Nitrile } \\
\text { Powder Free }\end{array}$ & 0108003959 & $\begin{array}{l}\text { Ansell Healthcare } \\
\text { Products (Malaysia) }\end{array}$ & $0(0 \%)$ \\
\hline $\begin{array}{l}\text { Nitratouch } \\
\text { Powder Free }\end{array}$ & 0101203228 & $\begin{array}{l}\text { Ansell Medical } \\
\text { (Thailand) }\end{array}$ & $0(0 \%)$ \\
\hline $\begin{array}{l}\text { Polyco Finite } \\
\text { Nitrile } \\
\text { Powder Free }\end{array}$ & 9566 & $\begin{array}{l}\text { BM Polyco Ltd } \\
\text { (Enfield, UK) }\end{array}$ & $1(1 \%)$ \\
\hline $\begin{array}{l}\text { Safeskin Xtra } \\
\text { Purple (Nitrile) } \\
\text { Powder Free }\end{array}$ & 01895-1 & $\begin{array}{l}\text { Safeskin Corp } \\
\text { (California) } \\
\text { Made in Thailand }\end{array}$ & $2(2 \%)$ \\
\hline $\begin{array}{l}\text { Safeskin Blue } \\
\text { (Nitrile) } \\
\text { Powder Free }\end{array}$ & $10655-1$ & $\begin{array}{l}\text { Safeskin Corp } \\
\text { (California) } \\
\text { Made in Thailand }\end{array}$ & $0(0 \%)$ \\
\hline
\end{tabular}




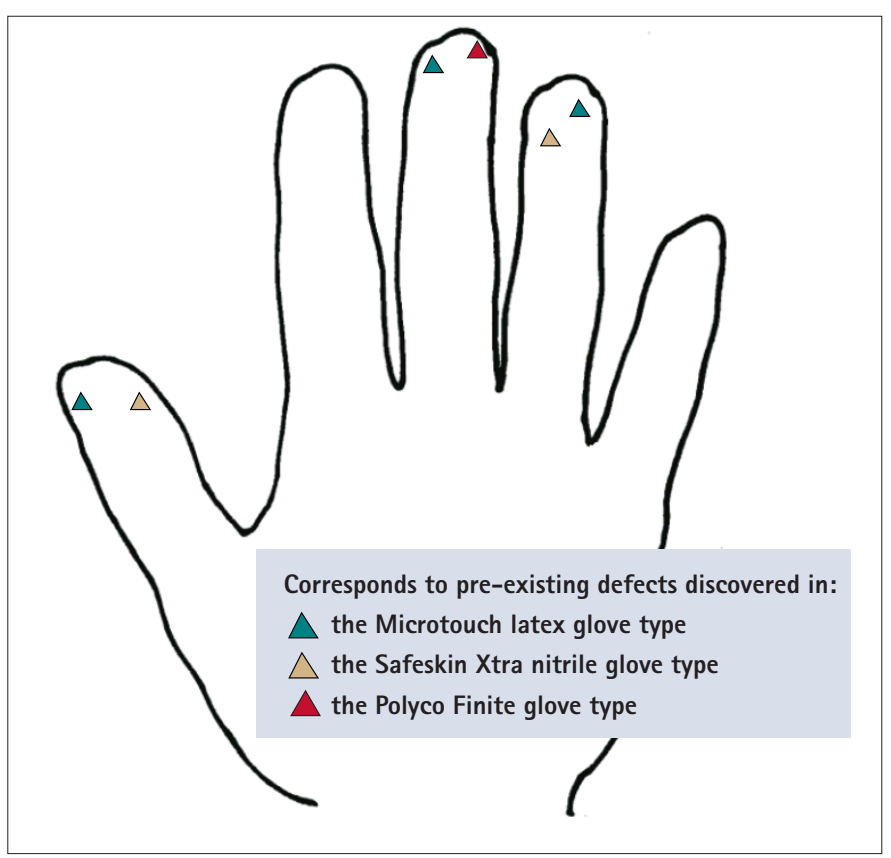

Fig. 1 The incidence and positioning of the pre-existing pinhole defects discovered in a variety of dental examination gloves

Cottone $^{28}$ for 110 sterile latex surgical gloves and 100 non-sterile latex examination gloves. These authors reported pre-existing pinhole defects in 1.8\% (2 of 110) of surgical and 2\% ( 2 of 100) of examination gloves indicating no significant variation between surgical and examination latex gloves. Further studies employed similar experimental technique, with Baggett and co-workers ${ }^{29}$ reporting that $0.7 \%$ ( 1 of 146) of latex gloves assessed were perforated before use and Murray et al. ${ }^{34}$ reporting pre-existing pinhole defects in 2.5\% (5/200) of latex gloves and 5.5\% (11/200) in the one nitrile glove that was assessed. However, Ballbach et al. ${ }^{26}$ stated that water inflation as an experimental technique generally provided an underestimation of the pre-existing pinhole defects present in the glove sample under investigation. Murray et al. ${ }^{24}$ held the glove filled with $500 \mathrm{ml}$ of water against a black background while gentle pressure was applied at the cuff and it is possible that the increased incidence of pre-existing pinhole defects recorded when compared with previous studies ${ }^{21,26-29}$ may have resulted from the darker background used by the authors.

The results of the current study indicate that the powdered latex examination glove assessed had a higher incidence of preexisting pinhole defects compared with both the surgical nonsterile latex gloves evaluated and the five nitrile glove types examined. Although the finger inflation water submersion technique used on latex gloves was proven previously ${ }^{21}$ to be a more accurate method of pre-existing pinhole determination, no extra defects were discovered than when the whole glove was inflated and water submerged. The results for the latex gloves are similar to those obtained previously for the latex examination gloves assessed using the water inflation method by Otis and Cottone. ${ }^{28}$ Murray et $a l .{ }^{24}$ reported that $2.5 \%$ of latex and 5.5\% of nitrile gloves assessed using the water inflation method had pre-existing pinhole defects. The nitrile gloves assessed by Murray et al. ${ }^{24}$ namely NitraTex (Ansell, London, UK), had a larger, but not significantly different, incidence of pre-existing pinhole defects when compared with the nitrile gloves in the current study. However, Murray et al. ${ }^{25}$ examined a larger number of gloves $(n=200)$ per group than in the present study, although only one nitrile glove type was considered.

The three pre-existing pinhole defects discovered in the powdered latex examination gloves assessed were located on the thumb, middle and ring finger portion of the gloves. These results corresponded with the findings of Katz et al. ${ }^{21}$ who reported that of the 132 latex gloves assessed 50\% (4/8) of the pre-existing pinhole defects had occurred on the middle finger and 37.5\% (3/8) had occurred on the thumb. The one pre-existing pinhole defect discovered in the second nitrile glove type was on the middle finger of the glove. Katz et $a l .{ }^{23}$ also reported that for unused latex gloves $87.5 \%$ (7/8) of pre-existing pinholes were located in the finger portion, which disagrees with the findings of Patton and co-workers, ${ }^{30}$ who noted only $18 \%$ of pinhole defects confined to the finger region of the latex gloves.

Pre-existing pinhole defects may be difficult to avoid during glove manufacture due to the complexity of the solvent dip process, in which a calcium ion binder is used to coat a clean porcelain former. This leaves a calcium/soap complex on the former allowing the particles to agglomerate into a film around the former. The length of time for which the former is dipped into the emulsion of polymer in water (latex) and the cleanliness of the former determines the quality of the film and thus contributes to the number of defects produced.

All single use examination gloves assessed for pinholes must be manufactured to an acceptable quality level (AQL) of 1.5 according to EN455-125. All of the gloves examined in the current study, using the air inflation/water submersion technique, comply with the AQL level of 1.5. This means that, in a large sample of gloves, the defect level will not be more than 1.5\%. However, as a relatively small sample (100 gloves) was considered in the current study, the AQL level of 1.5 dictates that the probability of having three pinhole defects is as high as $12.6 \%$, the probability of having two is $33.6 \%$ and the chances of having zero defects is $22.1 \%$.

All results obtained in the current investigation relate to a single batch for each glove examined, thus batch variation was not assessed. However, reputable manufacturers who employ good manufacturing procedures should not be susceptible to batch variation. Whilst the air inflation/water submersion evaluation is subjective and operator dependent, subjectivity was minimised in the current study by using the same operator for all experimentation. The study was designed principally to test recently introduced nitrile glove types, thus accurate comparisons based on only two types of latex gloves may not be valid. It was possible only to test the fingers of the latex gloves, hence a more thorough method for pre-existing pinhole detection as described by Katz ${ }^{21}$ was used. However, in the current study all pre-existing pinhole defects detected using glove finger inflation/water submersion technique were previously detected when inflating and submerging the whole latex glove. The documented incidence of pre-existing pinhole defects for the nitrile gloves examined indicated that these gloves could provide reliable barrier protection. However, parameters such as flexibility, fit and comfort must be assessed before nitrile gloves can be recommended for increased clinical use or suggested as a viable alternative to latex gloves, particularly the powdered type which carry a risk of sensitisation from inhalation of aeroallergens bound to glove powder.

\section{CONCLUSION}

In general, the incidence of pre-existing pinhole defects in the dental examination gloves assessed in the current study was lower than levels reported in previous studies. The nitrile gloves investigated exhibited less pre-existing pinhole defects than the latex glove types although the differences were not significant. The nitrile gloves tested could therefore be considered to provide reliable barrier protection.

The authors acknowledge the financial support of Ansell, Surbiton, Surrey, KT6 $6 A L$, United Kingdom for this study.

1. Centres of Disease Control. Recommended infection control practices for dentistry. Morb Mortal Wkly Rep 1986; 35: 237-242. 
2. British Dental Association. Guide to blood borne viruses and the control of cross infection in dentistry, 1987

3. Burke F JT, Wilson N H F, Martin M V, Field E A. Barrier techniques for protection of dental workers and patients. Infection control supplement 3. Dent Update 1997; 24: $1-10$.

4. Burke F J T. Use of non-sterile gloves in clinical practice. J Dent 1990; 18: 79-89.

5. Burke F JT, Wilson N H F. Non-sterile glove use: a review. Am J Dent 1989; 2: 255-261.

6. Walsh LJ, Lange P. Savage N W. Factors influencing the wearing of protective gloves in general dental practice. Quintessence Int 1995; 26: 203-209.

7. Miller C H. Infection control - infectious diseases and dentistry. Dent Clin North Am 1996: 20: 437-456

8. Ramos-Gomez F, Ellison J, Greenspan D, Bird W, Lowe S, Gerberding J L. Accidental exposure to blood and body fluids among health care workers in dental teaching clinics: a prospective study. J Am Dent Assoc 1997; 128: 1253-1261.

9. Martin M V , Burke FJ T, Field E A, Wilson N H F. Infection control: why bother? Infection control supplement 1. Dent Update 1996; 23: 1-4.

10. Centres of Disease Control. Recommendations for prevention of HIV transmission in health care settings. Morb Mortal Wkly Rep 1987; 36 (Supp no. 2S).

11. Centres of Disease Control. Recommended infection- control practices for dentistry. Recommendations and Reports. Morb Mortal Wkly Rep 1993; 42: RR-8.

12. Palmer $G D$, Fleming $G J P$. The management of occupational exposures to blood and saliva in dental practise. Dent Update 2000; 27: 318-324.

13. Kearns H P O, Burke FJ T, Cheung S W. Cross infection control in dental practice in the Republic of Ireland. Int Den J 2001; 51: 17-22.

14. Field E A. Hand hygiene, hand care, and hand protection for clinical dental practice. Recommendations of the European Panel for Infection Control in Dentistry (EPICD). BrDent J 1994; 176: 129-135.

15. Burke F JT, Wilson N H F, Cheung SW. Trends in glove use by dentists in England and Wales. Int Dent J 1994: 44: 195-201.

16. Burke FJ T, Wilson N H F, Baggett FJ. Glove wearing by dental surgery assistants: the current position in England and Wales. Dent Update 1993:20: 385-387.

17. The Collins English Dictionary, 2nd Edition; 1989: 867.

18. Amin A, Palenik C J, Cheung SW, Burke FJ T. Latex exposure and allergy: a survey of general dental practitioners and dental students. Int Dent J 1998; 48: 77-83.

19. Field $E A$, King C M. Skin problems with routine wearing of protective gloves in dental practice. Br Dent J 1990; 169: 281-285.

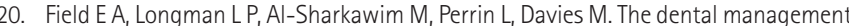
of patients with natural rubber latex allergy. BrDent J 1998; 185: 65-69.

21. Katz J N, Gobetti J P, Shipman C. Fluorescein dye evaluation of glove integrity. J Am DentAssoc 1989; 118: 327-331.

22. Jackson E M, Neal J G, Williams F M, Stern CA, Suber F, Thacker J G, Edlitch R F. Biomechanical performance of examination gloves. J Biomed Mater Res 1999; 48: 193-198.

23. Korniewicz, D M, Laughon, B E, Butz A, Larson E. Integrity of vinyl and latex procedure gloves. Nurs Res 1989; 38: 144-146.

24. Murray C A, Burke FJ T, McHugh S. An assessment of the punctures in latex and nonlatex dental examination gloves in routine clinical practice. Br Dent J2001; 190: 377-380.

25. EN455-1:2000. Specification for freedom from holes.

26. Ballbach $R$, Beavin $P$, Walters S M. A study of testing methods for the detection of defects in disposable latex and plastic gloves. J Assoc Off Analy Chem 1972; 55: 1074-1080.

27. Skaug N. Micropunctures of rubber gloves used in oral surgery. Int J Oral Surg 1976; 5: $220-225$.

28. Otis $L L$, Cottone $J A$. Prevalence of perforations in disposable latex gloves during routine dental treatment. J Am Dent Assoc 1989; 118: 321-324.

29. Baggett FJ, Burke FJ T, Wilson N H F. An assessment of incidence of punctures in gloves when worn for routine operative procedures. Br Dent J 1993; 174: 412-415.

30. Patton $L \mathrm{~L}$, Campbell $\mathrm{T} L$, Evers S P. Prevalence of glove perforation during double gloving for dental procedures. Gen Dent 1995; 43: 23-26. 